\title{
Alien species vs. native species: from community ecology to eco-evolutionary dynamics
}

\author{
Andersonn Silveira Prestes
}

\begin{abstract}
The establishment and spread of exotic species is a contemporary major concern. Alien species may become invasive in their new habitat, leading to both/either environmental and/or economic impacts. I briefly reviewed the literature in the last decade about the relationship of exotic species and native communities. I identified that professionals usually approach the subject in two main points of view: (1) researchers tend to point out the impacts of alien species on entire communities, evaluating if the relationship is positive, negative or neutral; (2) they focus on the eco-evolutionary processes involved in the introductions, the dynamics of invasion, and individual study cases. When evaluating the response of introductions to entire communities, evidence seems to be ambiguous and may support positive, negative or neutral relationship, especially depending on the scale approached. The unique eco-evolutionary pathways of each introduction may be a great shortcoming in the searching for generalities. On the other hand, advances have been made in understanding the dynamics of invasion on different lineages through a more selective/individualized approach. I suggest that the dynamics of invasion might be studied through a perspective in which different eco-evolutionary processes, levels of organization (from gene to entire communities), the history of the organism(s) and time are taken into account. Individual cases might be compared in attempt to understand how the relationship exotic and native works and in the search for generalities.
\end{abstract}


Keywords: exotic species; native communities; biological invasion; dynamics of invasion

\section{Introduction}

Human activity has been drastically changing the landscape on earth (Chapin et al., 2000). The introduction of organisms to regions that are different from their original distribution is a continuously increasing trend. Geographic barriers are losing their meaning and it has been claimed that earth is experiencing a New Pangea (Rosenzweig, 2001). The consequences have been documented, and among them are economic and environmental issues. Economically, pest species are rapidly increasing their ranges and reaching the most remote habitats (e.g. Haines et al., 2011). Environmentally, local species may decline or even become extinct due to the interference of the new inhabitants (Sax \& Gaines, 2008). Alien species is cited as a major cause of the current biodiversity crisis, being the second most important threat in United States, second only to habitat loss (Wilcove et al., 1998; see Rosenzweig, 2001 for an alternative view).

Biodiversity, comprising both alien and native species, is responding to the changing distributional patterns in different ways. Ecological empirical and theoretical works frequently focus on the patterns in the community structure and resistance to invasion (Kennedy et al., 2002; Sax, 2002; Herben et al., 2004; Borges et al., 2006). Otherwise, other professionals tend to point out the role of adaptive pressures and 
others evolutionary processes according to the introductions (Lee, 2002; Cox, 2004; Prentis et al., 2008; Suarez \& Tsutsui, 2008).

Here, I briefly review the relationship between exotic species and native communities in the last decade (year 2000 to 2010), considering both views stated above. Additionally, I will state the importance in recognizing the particularities and mechanisms related to specific introductions.

\section{Relationship exotic vs. native species: what do ecological communities tell us?}

The ecology of invasion has been a subject of study for decades (Elton, 1958). By trying to understand the susceptibility of natural communities to invasion, ecologists have reported different results in the relationship between exotic vs. native species.

Kennedy et al. (2002) pointed out the role of biodiversity in resisting biological invasion. They suggested that on small scales there is a negative relationship between exotic and native species. Their experiment, based on the increase of grassland diversity in small spots, demonstrated that more diverse spots had few successful invasions, both in number and proportion of invaders. Theoretically, the diversity resistance hypothesis is intuitively appealing: the high diversity rate might fill ecological niches, increase competition and, therefore, diminish opportunities for exotic species.

Nevertheless, positive relationship between native and exotic is frequently found as well (Lonsdale, 1999; Sax, 2002; Brown and Peet, 2003). Sax (2002), by studying plant diversity in California and Chile, reported that native and exotic species 
were strongly positively correlated across different spatial scales, and suggested, together with additional evidence from literature, that the correlation might be general. The theoretical explanation is related to facilitation processes, where sites ideal for native species might be ideal for non-native as well.

Following the discussion between positive and negative results, Herben et al. (2002) proposed a neutral model to explain the relationship native vs. exotic species. They stated that the problem is probably scale-dependent. The main argument asserts that usually small-scaled laboratory experimental studies show negative relationship, while broad-scaled regional observations demonstrate the opposite. Additionally, larger areas tend to have more invaders due to species-area relationship: as greater is a region, more diversity it tends to have. Finally, they claim that the neutral model fits such scaledependant problem and, while no further evidence arises, neutral processes might be responsible for the relationship between indigenous and non-indigenous species.

Yet, Borges et al. (2006) returned to the saturated environment or diversity resistance hypothesis when studying arthropods on a young volcanic island in the Azores. Islands, well known as biological test tubes for ecological and evolutionary investigations (Losos and Ricklefs, 2009), may offer interesting insights in the relationship between exotic and native species. Borges et al. (2006) proposed an invasion time model for the island endemic and non-native species. It considers invasibility and the temporary dynamic of the island: recent islands might be more susceptible to invasion because the native community is unsaturated. While proposing an invasion time model, Borges et al. (2006) showed a positive relationship between native and invasive species, explained by a probably facilitation process. Also, their main conclusions stated that endemic species- 
richness appears to be strongly related to abiotic factors, whilst non-indigenous species may be linked with disturbed sites. Hence, alien species might have been taking advantage of anthropogenic landscapes.

In this brief overview, it is clear that evidence appears to demonstrate some degree of ambiguity and supports competitor assumptions. The responses seem to vary, probably in a great degree, due to the organisms' own evolutionary histories and ecological paths, considering both exotic and natives. This explicit shortcoming might reinforce the particularity of each introduction and its potential to become a widespread invasion.

\section{Biological introductions: eco-evolutionary perspective}

Efforts have been made to understand the dynamics and particular processes involved in species introductions (Lee, 2002; Cox, 2004; Strauss et al., 2006; Prentis et al., 2008; Suarez \&amp; Tsutsui, 2008). Prentis et al. (2008), in their paper about adaptive evolution in plants, reviewed the role of bottlenecks, environmental stress, polyploidy, hybridization and standing variation in the key stages of plant invasions. During the time of invasion - between the introduction, spread and new range limit - all processes have their effects during the different phases. The initial moment is the most critical, where all processes would be operating simultaneously with the geographic, reproductive and environmental barriers to invasion. They suggest a genetic approach to identify genes or genetic changes that may be involved with one successful invasion, arguing in favor of this strategy to answer some fundamental questions related to 
adaptive evolution in alien species. Interesting problems could be addressed with such approach like what would be the role of standing genetic variations and new mutations in a successful invasion, as well as how selection would operate in multiple independent invasions.

Another crucial issue in the introduction of species is the time of invasion. It certainly varies considerably between exotic taxa in different places, and sometimes a population size or genetic threshold needs to be achieved to promote the establishment and invasion. Still, there are cases whose invasion time may be astonishingly rapid. Few generations might be required to fulfill the steps between introduction and invasiveness (Lee, 2002).

Moreover, the success of an alien species in the new region may not be accidental; its natural history and set of adaptations in its native range can be very informative when evaluating and understanding its invasibility potential (Hierro et al., 2005; Le Roux et al., 2007; Suarez \& Tsutsui, 2008). Further, comparing species original natural history with the responses in the new invaded area can provide unique insights about the evolutionary and ecological theory (Hierro et al., 2005; Le Roux et al., 2007).

Native communities also respond to introductions, suffering different ecological and evolutionary pressures (Strauss et al., 2006; Suarez \& Tsutsui, 2008). Strauss et al. (2006) stressed these consequences, correlating population size and ecological impact: when invasive species affect the ecology and genotypes of natives, a strongly evolutionary response may arise. Native species can change their allele frequencies towards a fitter phenotype. Still, the interaction may change local range sizes, affect the lineages ecospace and cause severe decline in less resilient local populations. 
Finally, the studies presented in this section consider an eco-evolutionary perspective through the biological problem. When approached, it becomes clear that there are many peculiarities of each introduction. Probably a search for broader patterns might be greatly benefited by understanding individual cases and how natives and aliens behave in this new changing environment.

\section{Conclusions}

By studying the relationship between exotic and native species, different results may be encountered, either being negative, positive or neutral. In these studies, the view through the scientific target is broad and considers the whole community responding to the introductions. Such an approach is certainly valid and presents interesting insights.

Regardless, individual approaches may proportionate a more detailed study on processes and mechanisms in the dynamics of invasion (see Le Roux et al., 2007 as an example of a successful invader). Each invasion and invaders have their own particularities. The major challenge might be to understand the processes and pathways involved in the biological introduction, both implying the reciprocal responses from native community and alien species.

Finally, I suggest that empirical and theoretical studies could call attention to the relationship between native and non-native populations through a perspective that regards different eco-evolutionary processes, levels of organization (from gene to entire communities), the history of the organism(s) and time of individual cases. For example, a 
given process may occur in a genetic basis during certain amount of time when the exotic species is establishing itself in the new environment - evaluating the former history of the non-native species. In a higher level, species interactions between exotic and native species may reveal a process of strong competition and further ecological release of the exotic species after a certain time, which is explained and directly related to the habits of the invader in its native range. To identify mechanisms of change along time considering an historical basis may greatly improve our understanding in the dynamics of invasion.

Additionally, individual cases might be compared in order to extrapolate common patterns. Regularities might be identified, at least for certain lineages, and there might be certain ways to manipulate the system. At last, it would be worth to identify barriers to invasion, ways to manage native species and how the invasion dynamics works itself.

\section{Acknowledgements}

I thank Sheila Conant and Cliff Morden for reading through the manuscript. 


\section{References}

Borges, P. A. V.; Lobo, J. M.; Azevedo, E. B.; Gaspar, C. S.; Melo, C.; and Nunes, L. V. 2006. Invasibility and species richness of island endemic arthropods: a general model of endemic vs. exotic species. Journal of Biogeography, 33, 169-187.

Brown, R. L. and Peet, R. K. 2003. Diversity and invisibility of southern Appalachian plant communities. Ecology, 84, 32-39.

Chapin, F. S.; Zavaleta, E. S.; Eviner, V. T.; Naylor, R. L.; Vitousek, P. M.; Reynolds, H. L.; Hooper, D. U.; Lavorel, S.; Sala, O. E.; Hobbie, S. E.; Mack, M. C.; and Diaz, S. 2000. Consequences of changing biodiversity. Nature, 405, 234-242.

Cox, G. W. 2004. Alien species and evolution. Island Press, 400p.

Elton, C. S. 1958. The ecology of invasions by animals and plants. The University of Chicago Press, 181p.

Haines, W.; Starr, F.; Starr, K.; King, W. G. 2011. New record of the fruit piercing moth Oraesia excavata (Butler) (Erebidae: Calpinae: Calpini) for Hawaii and the United States. Journal of the Lepidopterists' Society, 65, 53-57. 
Herben, T.; Mandak, B.; Bimova, K; and Munzbergova, Z. 2004. Invasibility and species richness of a community: a neutral model and a survey of published data. Ecology, 85, 3223-3233.

Hierro, J. L.; Maron, J. L.; and Callaway, R. M. 2005. A biogeographical approach to plant invasions: the importance of studying exotics in their introduced and native range. Journal of ecology, 93, 5-15.

Kennedy, T. A.; Naeem, S.; Howe, K. M.; Knops, J. M. H.; Tilman, D.; and Reich, P. 2002. Biodiversity as a barrier to ecological invasion. Nature, 417, 636-638.

Lee, C. E. 2002. Evolutionary genetics of invasive species. Trends in Ecology and Evolution, 17, 386-391.

Le Roux, J. J.; Wieczorek, A. M.; Wright, M. G.; and Tran, C. T. 2007. Super-genotype: global monoclonality defies the odds of nature. PLOS one, 2(7):e590. doi:10.1371/journal.pone.0000590

Lonsdale, W. M. 1999. Global patterns of invasions and the concept of invasibility. Ecology 80, 1522-1536.

Losos, J. B. and Ricklefs, R. E. 2009. Adaptation and diversification on islands. Nature, 457, $830-836$. 
Prentis, P. J.; Wilson, J. R. U.; Dormontt, E. E.; Richardson, D. M.; and Lowe, A. J. 2008. Adaptive evolution in invasive species. Trends in Plant Sciences, 13, 288-294.

Rosenzweig, M. L. 2001. The four questions: what does introduction of exotic species do to diversity? Evolutionary Ecology Research, 3, 361-367.

Sax, D. F. 2002. Native and naturalized plant diversity are positively correlated in scrub communities of California and Chile. Diversity and Distribution, 8, 193-210.

Sax, D. F. and Gaines, S. D. 2008. Species invasions and extinction: the future of native biodiversity on islands. Proceedings of the National Academy of Science, 105, 1149011497.

Strauss, S. Y.; Lau, J. A.; and Carroll, S. P. 2006. Evolutionary responses of natives to introduced species: what do introductions tell us about natural communities? Ecology Letters, 9:357-374.

Suarez, A. V. and Tsutsui, N. D. 2008. The evolutionary consequences of biological invasions. Molecular ecology, 17, 351-260.

Wilcove, D. S.; Rothstein, D.; Dubow, J.; Phillips, A.; and Losos, E. 1998. Quantifying threats to imperiled species in the United States. Bioscience, 48, 607-615. 